\title{
Non-parallel double-crack propagation in rock-like materials under uniaxial compression
}

\author{
Weidong Pan ${ }^{1,3,4} \cdot$ Xin Wang ${ }^{2}$ Qiming Liu ${ }^{1,3,4} \cdot$ Yongkang Yuan ${ }^{1,3,4}$ • \\ Baodong Zuo ${ }^{1,3,4}$
}

Received: 23 December 2018/Revised: 17 March 2019/Accepted: 8 May 2019/Published online: 31 May 2019

(C) The Author(s) 2019

\begin{abstract}
Coalescence among fractures would have influence on the stability of rock masses. Deep understanding of mechanical behavior of fractured rock masses is an important mean to identify failure mechanism of geological disaster. In this study, crack propagation processing was studied through loading pre-fractured specimens of concrete block, termed as rock-like material, in uniaxial compression tests. New non-parallel double-crack geometry was introduced to observe crack coalescence. The flaw combinations are different from the normally used flaw configurations. In addition, ultrasonic detection tests were performed on the test blocks. The stress and strain data of these tests and characteristic parameters of sound wave were recorded. The stress-strain curves of each test block under the uniaxial compression test were drawn, relations among deformation characteristics and crack angle of the crack specimens, and their overall strength were analyzed. It is found that strength of the specimen decreases as crack inclination increases under two crack inclinations. The highest uniaxial compressive strength is found in the specimen with the cracks at the same angle in different directions. Based on description of the crack initiation location, crack surface and the ultimate failure patterns, failure modes of eight subtype for test blocks are divided into three categories. It is expected that the study results could be beneficial for engineering application of jointed rock masses.
\end{abstract}

Keywords Rock-like material · Non-parallel double cracks · Crack-propagation path · Uniaxial compression test

\section{Introduction}

Weidong Pan

pwd@cumtb.edu.cn

1 State Key Laboratory of Coal Resources and Safe Mining, China University of Mining and Technology, Beijing 100083, China

2 MIRARCO-Mining Innovation, Laurentian University, Sudbury P3E 2C6, Canada

3 Key Laboratory for Precise Mining of Intergrown Energy and Resources, China University of Mining and Technology, Beijing 100083, China

4 Coal Industry Engineering Research Center of Top-Coal Caving Mining, Beijing 100083, China

A large number of structural plane are formed inside the rock mass under influence of geological progress, which have a significant effect on strength and failure form of rock masses. In most cases, the mechanical properties of the structural plane determine the overall mechanical properties of the rock masses. It is well known that fracture propagation often leads to the failure of rock masses, in this manner, many researches are focused the field of crack propagation.

Shao et al. (2011) studied the failure process of tensile crack under different crack generating conditions by using rock-like materials. They obtained various failure modes of crack propagation under different generating conditions. Chen et al. (2005) used CT scanning to study the propagation law of intermittent cracks; Li et al. (2010) selected ceramics as the basic material for fabricating specimens 
with two round coin-shaped cracks in the middle; they performed real-time CT scan tests, under a uniaxial compression load, and studied the expansion and damage laws of double fractures in the specimens. Wong and Chau (1998) obtained the propagation and connection rule of each crack through the compression failure testing of rock, with multi-crack specimens. Through unidirectional compression and bidirectional compression experiments on numerous rock materials with single cracks, Bobet and Einstein (1998) categorized the crack propagation of rock specimens with single cracks into seven common types. Wong and Einstein (2009a, b) used a fast, high-definition camera to observe the failure modes of marble and gypsum specimens containing two sets of parallel cracks, under uniaxial compression, and categorized them into nine common parallel-crack connection modes. Brooks et al. (2013) established the direction and form of crack propagation using Nano indentation technology. Yang et al. (2009) used a rock mechanics servo-control testing machine to conduct uniaxial compression experiments on brittle marble with intermittent precast fracture and analyzed the influence of the geometric distribution of the fracture parameters on the deformation and failure characteristics of marble. Zhu et al. (2016) fabricated a batch of samples with single and double internal fractures using transparent rock-like materials. They studied the influence of crack propagation and the penetration modes of single and double crack specimens under different rock bridge dip angles and crack spacing; they also studied the influence of the number and spacing of the cracks on the compressive strength of the specimens. Shen et al. (2016) studied the damage evolution and crack propagation process in specimens with double cracks by prefabricating double cracks in real rock specimens, using the MTS servo-control testing machine in uniaxial and triaxial compression. Yang (2013) studied the influence of the dip angle in rock bridge on the strength failure and crack propagation characteristics of fractured three-crevasse sandstone through uniaxial compression tests on fractured three-crevasse sandstone samples. $\mathrm{Pu}$ et al. (2010) performed uniaxial loading experiments on rock-like materials with multiple fissures, and they researched the influencing laws of the fracturefailure strength of rock-like material, at various fissure angles and densities.

From the above literature, most of studies are focused on single cracks or parallel multiple cracks. However, rock masses usually contained non-parallel crack in nature and non-parallel crack is a common form in rock masses. Zhang et al. (2015a, b) conducted uniaxial compression tests on specimens containing intersecting multi-flaws and studied the influence of primary and secondary cracks on the specimen strength. Apart from the intersecting flaws, rocks were also composed of uncross and unparallel flaws.
Lee and Jeon (2011) carried out uniaxial compression experiments on three materials containing two unparallel flaws. They concluded the materials had an effect on the pattern of crack initiation and propagation. Ren et al. (2017) researched two new types of coalescence modes, namely, the dihedral and annular modes, by numerical simulation of the uniaxial compression of rock-like materials containing two non-parallel cracks. Huang et al. (2016) investigated strength failure and cracking behavior of rock-like material specimens by using laboratory experiments and PFC3D, they stated that crack evolution process and failure mode are dependent on fissure angle and confining pressure. Yang et al. (2013) explored fracture coalescence behavior of red sandstone containing two unparallel fissures, which found that the cracking process of red sandstone depends on the fissure angle and the heterogeneity of rock material. Zhang et al. (2015a, b) numerically investigated crack coalescence between two non-parallel flaws, they stated that the different stress distribution in bridge area between non-parallel flaws and parallel flaws affects the stress for crack initiation as well as the pattern for coalescence. Afolagboye et al. (2017) investigated the influence of ligament length and ligament angle on the crack initiation and coalescence behavior of non-parallel flaws, they revealed that the crack initiation and coalescence behavior of rock-like specimens with nonparallel flaws are analogous to the cracking and coalescence pattern observed in specimens with parallel flaws.

However, above studies didn't fully address the influence of angle on crack cracking and coalescence behavior. To further investigate the cracking propagation between non-parallel flaws, this study formulated unique fracture patterns by different flaw combinations, which are different from the normally used flaw configurations. Fracture experiments were conducted on these non-parallel doublecrack rock materials. Laws of initiation, propagation, and penetration of non-parallel double cracks were studied. Test results can enrich the research field of crack propagation and it would be beneficial for the engineering applications of jointed rock masses.

\section{Uniaxial compression test for rock-like specimens with non-parallel double cracks}

Rock-like materials were used for simulating fractured rock masses in these test. The materials were mixed according to a mass ratio of 1:0.96:0.48 of cement: river sand: water. The sample size (length $\times$ width $\times$ height) was $10 \mathrm{~cm} \times 10 \mathrm{~cm} \times 10 \mathrm{~cm}$. An open crack was made by pre-inserting a thin metal sheet and pulling the sheet outward after the initial solidification of the specimen. To eliminate accidental error and enhance the scientific 


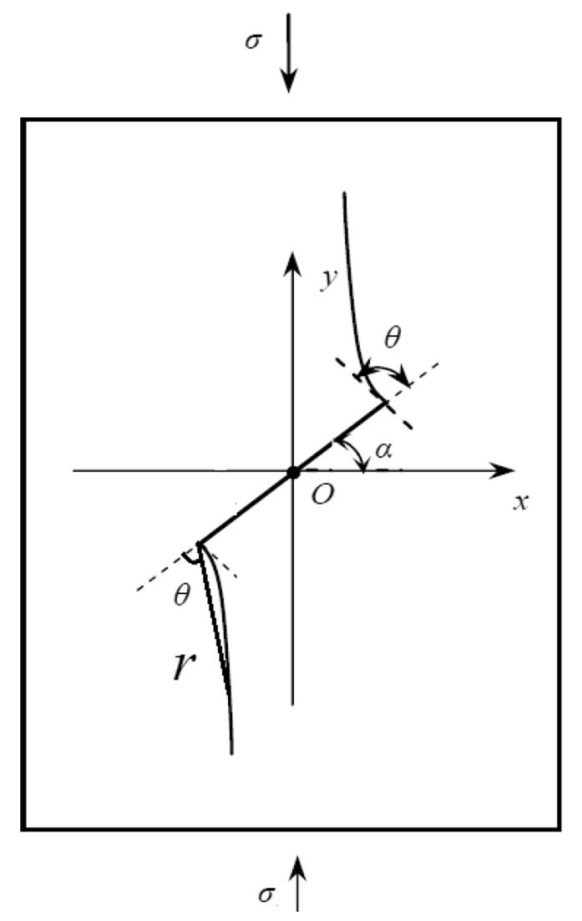

Fig. 1 Inclined crack propagation model

experiment, three identical prefabricated crack test blocks were prepared for each group, with a total of 12 groups. The prefabricated crack in this experiment was $2 \mathrm{~mm}$ wide and $20 \mathrm{~mm}$ long. The specimens were placed in a cool and ventilated location for 28 days.

In this experiment, the crack initiation angle, which is the angle between the tangential direction of the wing crack at the moment of crack initiation at the prefabricated crack tip and the long axis direction of the initial prefabricated elliptic crack, is indicated by $\theta$.

The dip angle of the prefabricated crack, which is an acute angle between the long axis of the prefabricated crack and the horizontal direction, is indicated by $\alpha$, as shown in Fig. 1.

Precrack angle combinations of $0^{\circ}, 30^{\circ}, 45^{\circ}, 60^{\circ}$ and $90^{\circ}$ were used for establishing the non-parallel double crack model; these included a combination of horizontal and inclined cracks, vertical and inclined cracks, cracks at the same dip angle, and inclined cracks with different inclination angles. Twelve types of non-parallel double crack combination modes were used in this experiment. The crack arrangement and specimen number of each specimen were depicted in Fig. 2. The acute angle between the prefabricated crack and the $x$-axis positive direction is indicated by $\alpha_{1}$, the acute angle between the prefabricated crack and the $x$-axis negative direction is indicated by $\alpha_{2}$.

The uniaxial compression test for the non-parallel double-crack specimens was performed using the electrohydraulic servo universal testing machine in the mine pressure laboratory of the China University of Mining and Technology (Beijing). The experimental system consists of test bed, loading control system and data acquisition system. The specimen was placed in the center of the base and kept horizontal contact with the base. During the experiment, the displacement loading rate was controlled to $1 \mathrm{~mm} / \mathrm{min}$. A computer software automatically collected the corresponding stress, strain, and time data from the elastic deformation, crack initiation, and failure of the specimens, the stress-strain curves were drawn for each test. The loading test was recorded using a high-speed camera to observe crack initiation, propagation, and coalescence (Figs. 3, 4).

\section{Test results and analysis of rock-like specimens with non-parallel double cracks}

\subsection{Analysis of the stress-strain relation of rock-like specimens with non-parallel double cracks}

In this uniaxial compression experiment, the stress-strain curves of specimens with different dip cracks are shown in Fig. 5.

In Fig. 5, it is observed that the combination of different inclination angles have large influence on the deformation and strength behavior of test specimens. For the horizontal and inclined crack combination, the strength decreases as the increasing of the inclined crack angle. The relation among the overall strength of the specimens is SQ60 < SQ45 < SQ30, and the peak strength of the SQ60 specimen is considerably lower than that from the other two specimens. Compared the deformation behavior among the three groups of specimens, when the stress reaches the peak value, it is observed that the deformation of the SQ45 specimens is the largest at the peak value; the relation among the deformation of the three groups, at the peak, is SQ45 > SQ30 > SQ60.

Compared the stress and strain curves of specimens with horizontal to the inclined crack combinations, there is an obvious decrease trend in the peak strength of specimens with vertical and inclined crack combinations, which is because the overall strength of the test block is considerably affected by the vertical crack. Compared to the other working conditions, the compressive crack at the vertical crack tip is more likely to crack and expand, in this fashion, it is not surprised that the strength of the specimen is the lowest. The vertical crack first appeared on the failure surface, parallel to the loading direction, verifies this conclusion. The relation among the peak strengths of the three test blocks is CQ30 > CQ45 > CQ60. With the increases in dip angle, the overall strength of the test block decreases. Comparing the deformation in the test block, when it 


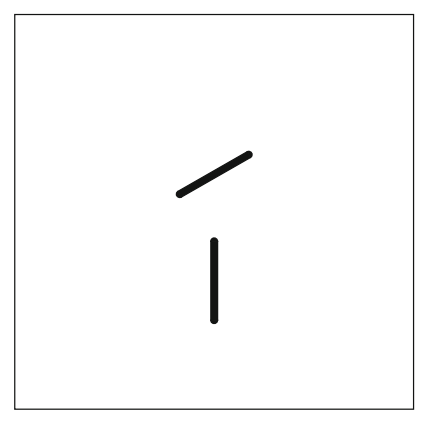

(a) CQ30

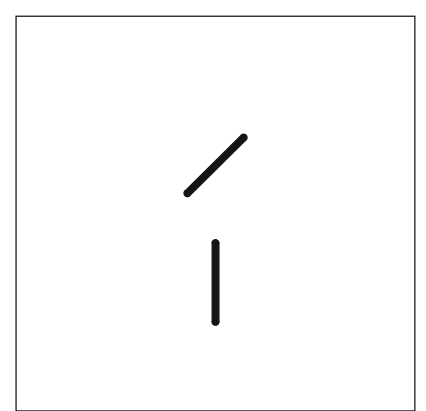

(b) $\mathrm{CQ} 45$

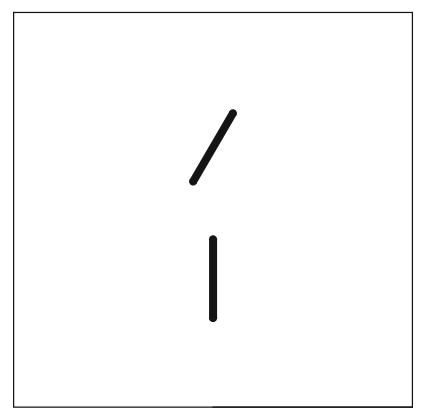

(c) CQ60

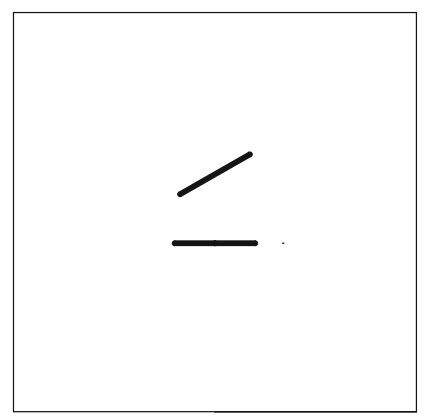

(d) SQ30

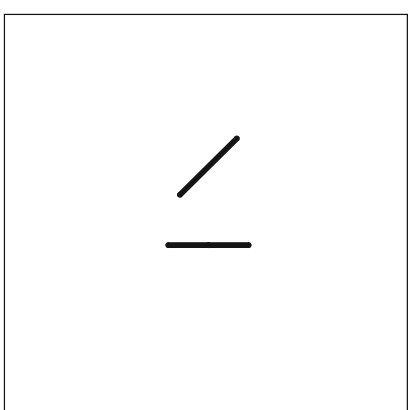

(e) SQ45

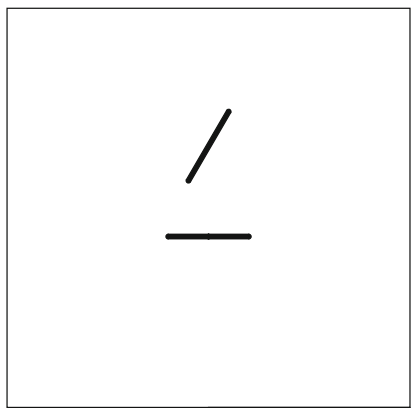

(f) SQ60

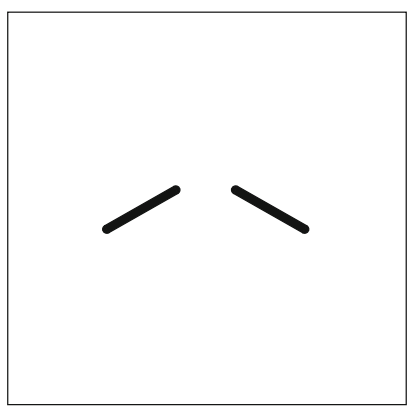

(g) DQ30

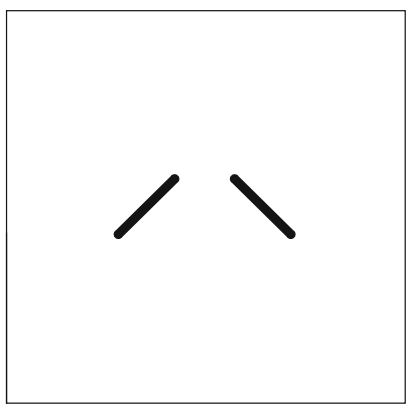

(h) DQ45

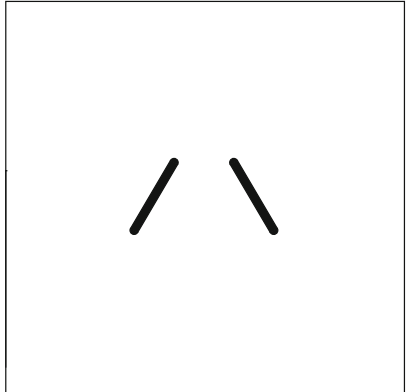

(i) DQ60

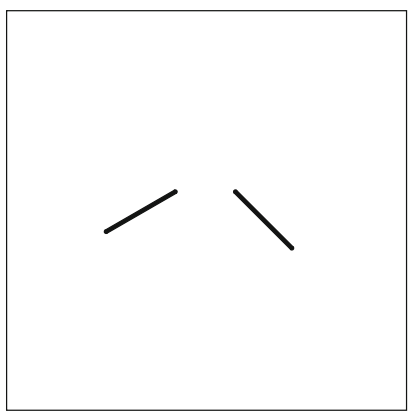

(j) SQ30-45

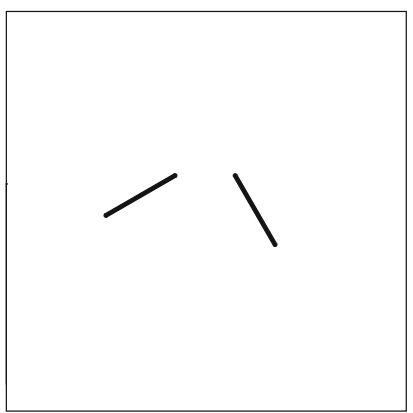

(k) SQ30-60

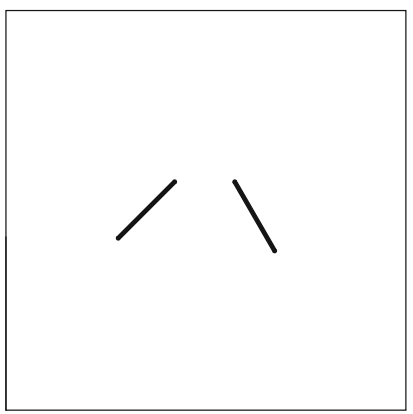

(l) SQ45-60

Fig. 2 Diagrams of the fractured specimens

reaches the peak strength, the deformation of the CQ60 test block is considerably lower than that from the other two groups; the specimen reaches the peak strength rapidly, which can cause instability and failure. The relation among the deformation of the three groups, at the peak strength, is CQ45 > CQ30 > CQ60.

Specimens with two cracks at the same dip angle have the highest strength; the peak strength of sample DQ30 reaches 


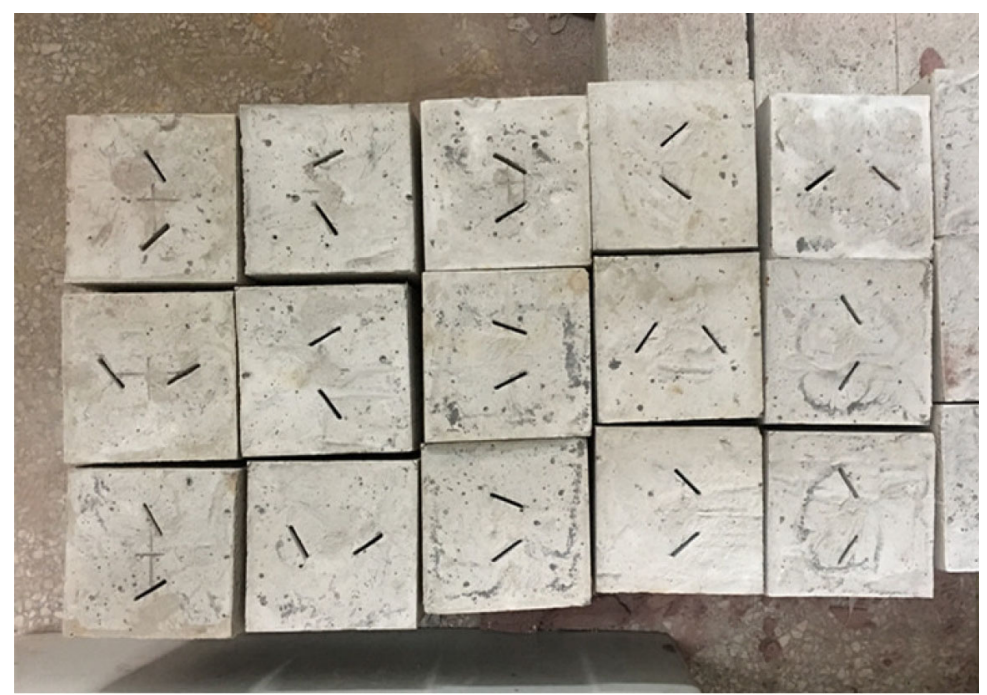

Fig. 3 Photos of part completed samples

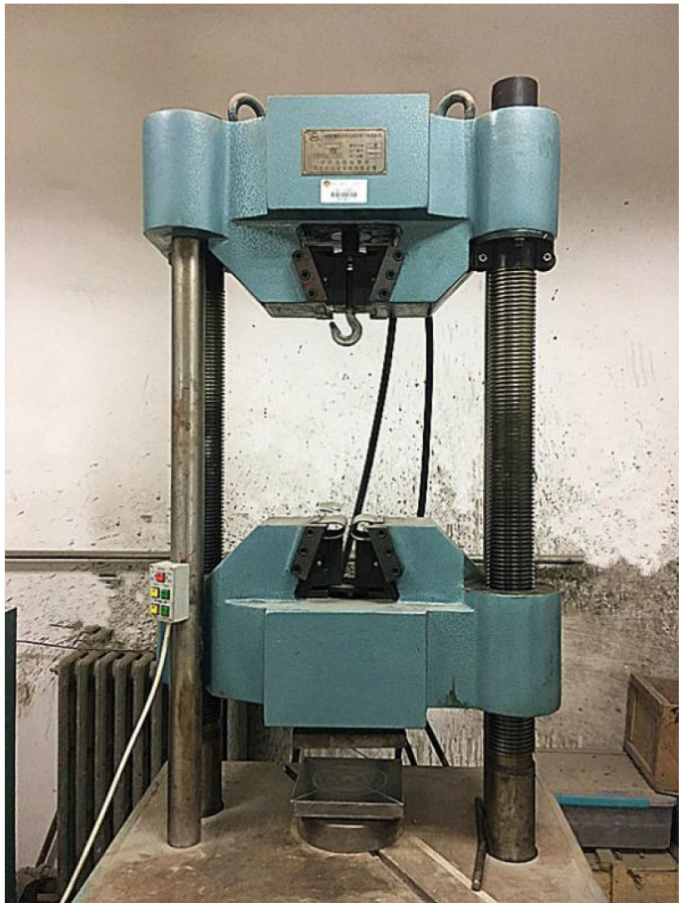

Fig. 4 Test equipment

33.7 MPa. For the combination of inclined cracks at different inclination angles, there is no significant difference in the strength of the three groups of specimens (Table 1).

In Fig. 5 and Table 2, it is observed that the peak stress was mostly distributed between 25 and $34 \mathrm{MPa}$. The crack stress is generally $60 \%-80 \%$ of the peak stress. The crack angle has considerable influence on the strength of the specimen, which decreases with the increasing of the crack inclination angle, for the combination of two different dip angles. For the combination of inclined cracks at the same dip angle in different directions, the strength of the specimen is obviously higher than those of the other combinations. For the combination with the same angle, the strength of specimen with two cracks at $45^{\circ}$ is the lowest.

\subsection{Analysis of the crack initiation and failure of rock-like specimens with non-parallel double cracks}

It can be seen from Table 2 that different combinations of non-parallel fractures have different effects on the crack initiation stress; the crack initiation stress of two crack specimens with the same dip angle is higher than those of the other combinations. In Fig. 6, it is observed that the crack initiation is mostly located at the end of the prefabricated crack, establishing that tip damage is caused by stress concentration. The initial crack of the prefabricated horizontal crack is less than that of the inclined crack; for a specimen with a small precast crack inclination, it mainly produces a wing crack that can develop stably in a preferred direction; when the precast crack angle is large, the generated wing crack decreases, and the shear crack increases. Some of the test blocks have plastic zones, where several visible micro cracks are generated. However, it is also found that a small part of the crack initiation is near the middle, and a secondary crack is generated at the initiation. With the increasing of the crack inclination angle, the main failure mode of the test block is gradually changed from tensile failure to shear failure. In particular, for a crack angle of $45^{\circ}$, shear failure is more obvious. Overall, the degree of damage to the test block, under uniaxial compression, increases with the increasing of the inclination angle; the damage intensity increases, and the overall crushing degree is large. Before the test block yields, the increase in strain with the increase 


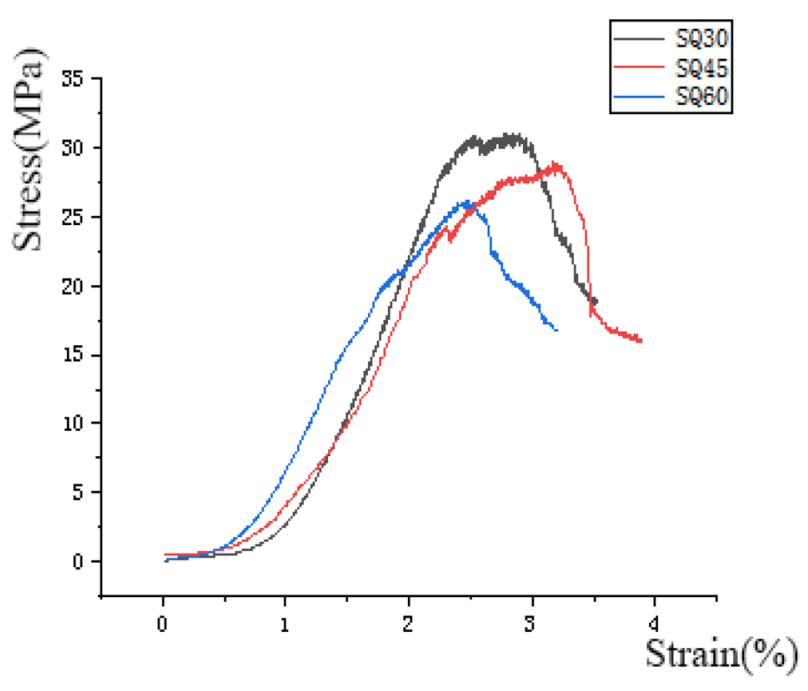

(a) Combination of a horizontal and inclined crack

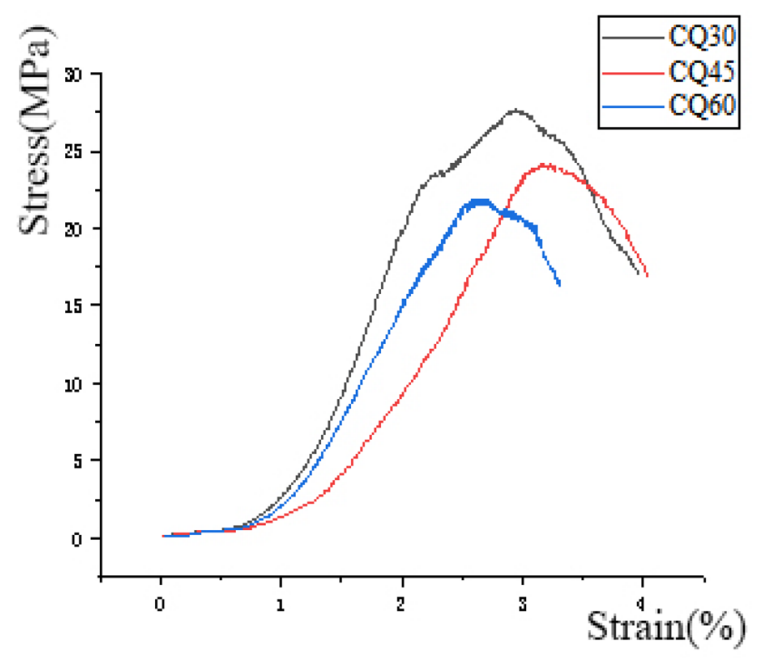

(b) Combination of a vertical and inclined crack

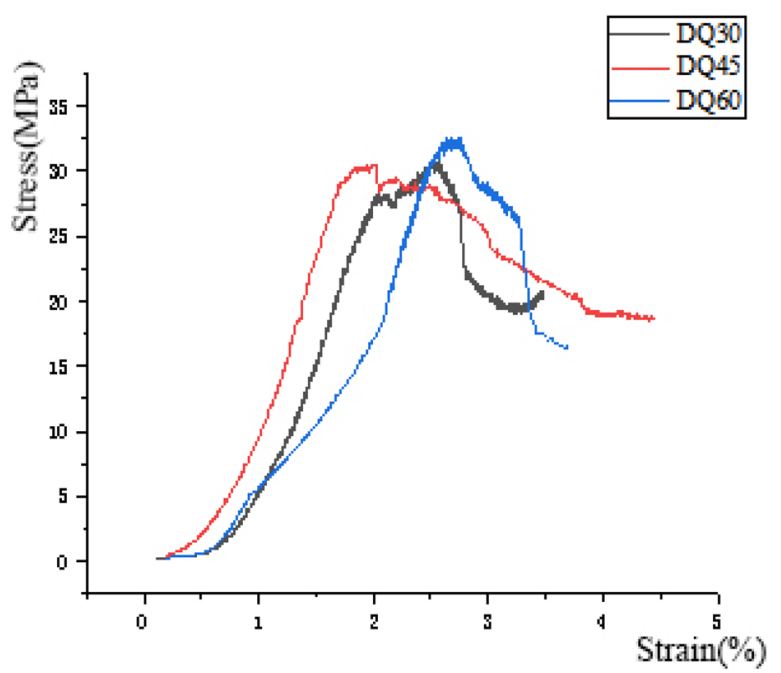

(c) Combination of inclined cracks at the same dip angle

Fig. 5 Stress-strain curves of specimen with different dip angles 


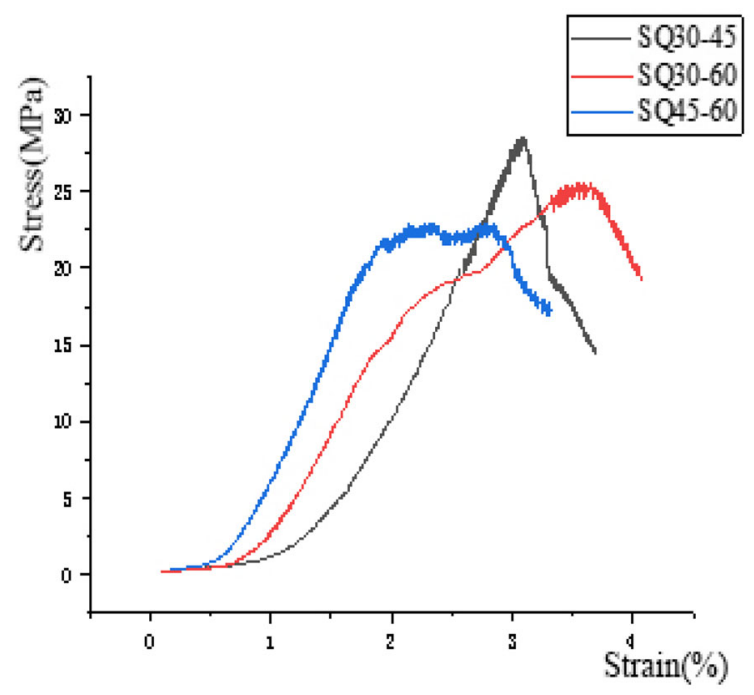

(d)Combination of inclined cracks at different inclination angles

Fig. 5 continued

Table 1 Test conditions

\begin{tabular}{llll}
\hline Number & Dip angle, $\alpha_{1}\left({ }^{\circ}\right)$ & Crack length $(\mathrm{mm})$ & Dip angle, $\alpha_{2}\left(^{\circ}\right)$ \\
\hline SQ30 & 30 & 20 & 0 \\
SQ45 & 45 & 20 & 0 \\
SQ60 & 60 & 20 & 0 \\
CQ30 & 30 & 20 & 90 \\
CQ45 & 45 & 20 & 90 \\
CQ60 & 60 & 20 & 90 \\
DQ30 & 30 & 20 & 30 \\
DQ45 & 45 & 20 & 45 \\
DQ60 & 60 & 20 & 60 \\
SQ30-45 & 30 & 20 & 45 \\
SQ30-60 & 30 & 20 & 60 \\
SQ45-60 & 45 & 20 & 60
\end{tabular}

in stress is not large, and the plastic deformation is not considerable. The test block accumulates more energy with the steady increases in stress and strain; however, the stored energy is released during the final stage of yield failure in large quantities, which result in a high degree of test block failure.

From the observation of the crack initiation, propagation, and development of the crack in the loading process, along with the analysis of the final failure pattern, the failure mode of the specimens are divided into three categories: tension coalescence failure, tension and shear composite coalescence failure, and shear coalescence failure. The failure modes are further divided into eight subclasses. The coalescence failure types of the cracked specimens are summarized in Table 3. According to the
Table 2 Test results for different conditions

\begin{tabular}{lrrlll}
\hline Number & $\begin{array}{l}\alpha_{1} \\
\left({ }^{\circ}\right)\end{array}$ & $\begin{array}{l}\alpha_{2} \\
\left({ }^{\circ}\right)\end{array}$ & $\begin{array}{l}\text { Crack } \\
\text { initiation stress } \\
(\mathrm{MPa})\end{array}$ & $\begin{array}{l}\text { Peak } \\
\text { stress } \\
(\mathrm{MPa})\end{array}$ & $\begin{array}{l}\text { Crack } \\
\text { penetration } \\
\text { stress (MPa) }\end{array}$ \\
\hline SQ30 & 30 & 0 & 18.5 & 30.8 & 27.7 \\
SQ45 & 45 & 0 & 16.8 & 28.1 & 25.2 \\
SQ60 & 60 & 0 & 16.1 & 26.8 & 24.1 \\
CQ30 & 30 & 90 & 15.9 & 26.5 & 23.9 \\
CQ45 & 45 & 90 & 13.1 & 21.8 & 19.6 \\
CQ60 & 60 & 90 & 12.5 & 20.4 & 18.7 \\
DQ30 & 30 & 30 & 20.2 & 33.7 & 30.1 \\
DQ45 & 45 & 45 & 18.5 & 30.9 & 27.8 \\
DQ60 & 60 & 60 & 20.1 & 33.4 & 30.1 \\
SQ30-45 & 45 & 30 & 15.8 & 26.4 & 23.8 \\
SQ30-60 & 60 & 30 & 15.6 & 25.9 & 23.3 \\
SQ45-60 & 60 & 45 & 14.7 & 24.5 & 22.1 \\
\hline
\end{tabular}

crack initiation position, occurrence of the wing crack, and the crack surface, the types of coalescence failure are described to explain the characteristics of each mode.

\section{Ultrasonic testing of rock-like specimens with cracks}

In this experiment, ultrasonic testing are carried out for the 12 test blocks, before and after uniaxial compression test. Various acoustic parameters of the test block, before and after uniaxial compression, are monitored. By comparing and analyzing the data, the influence of the dip angle on the 

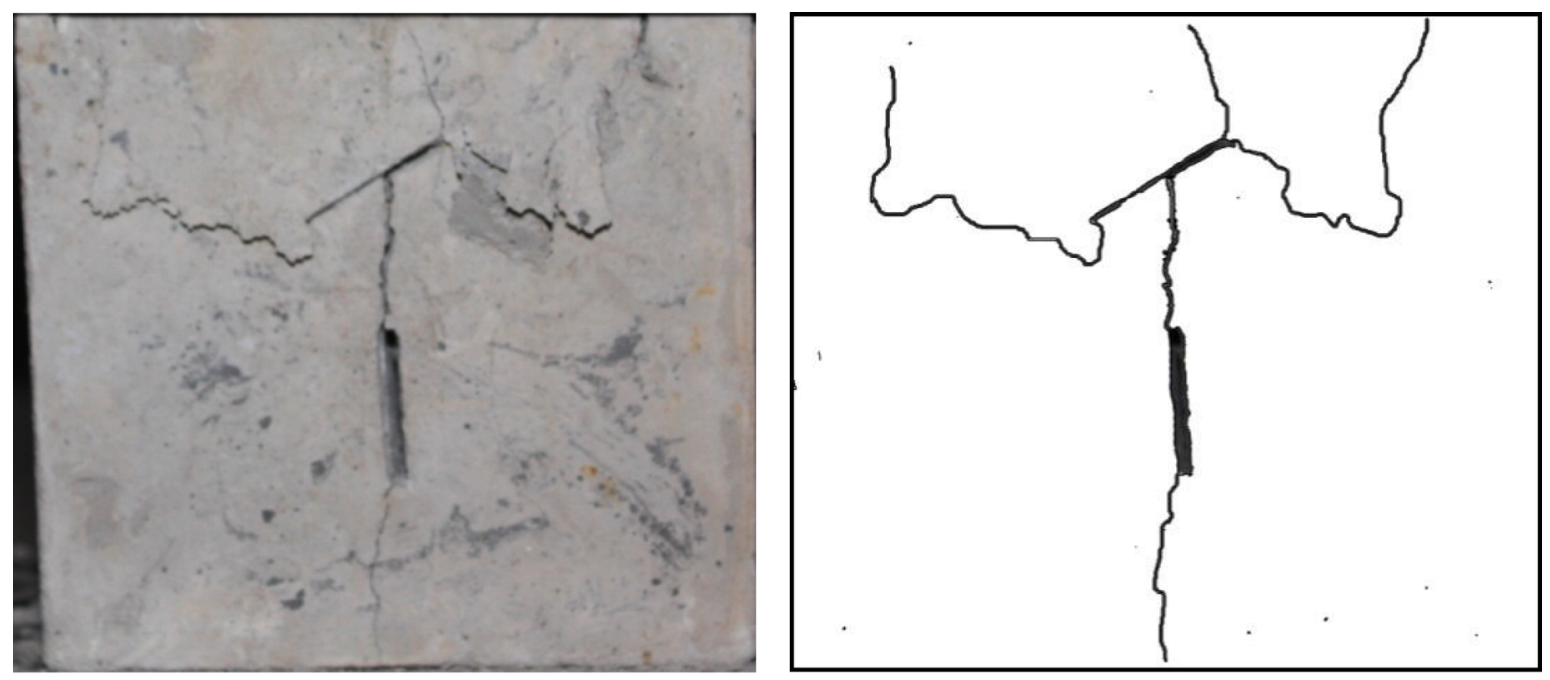

(a) CQ30
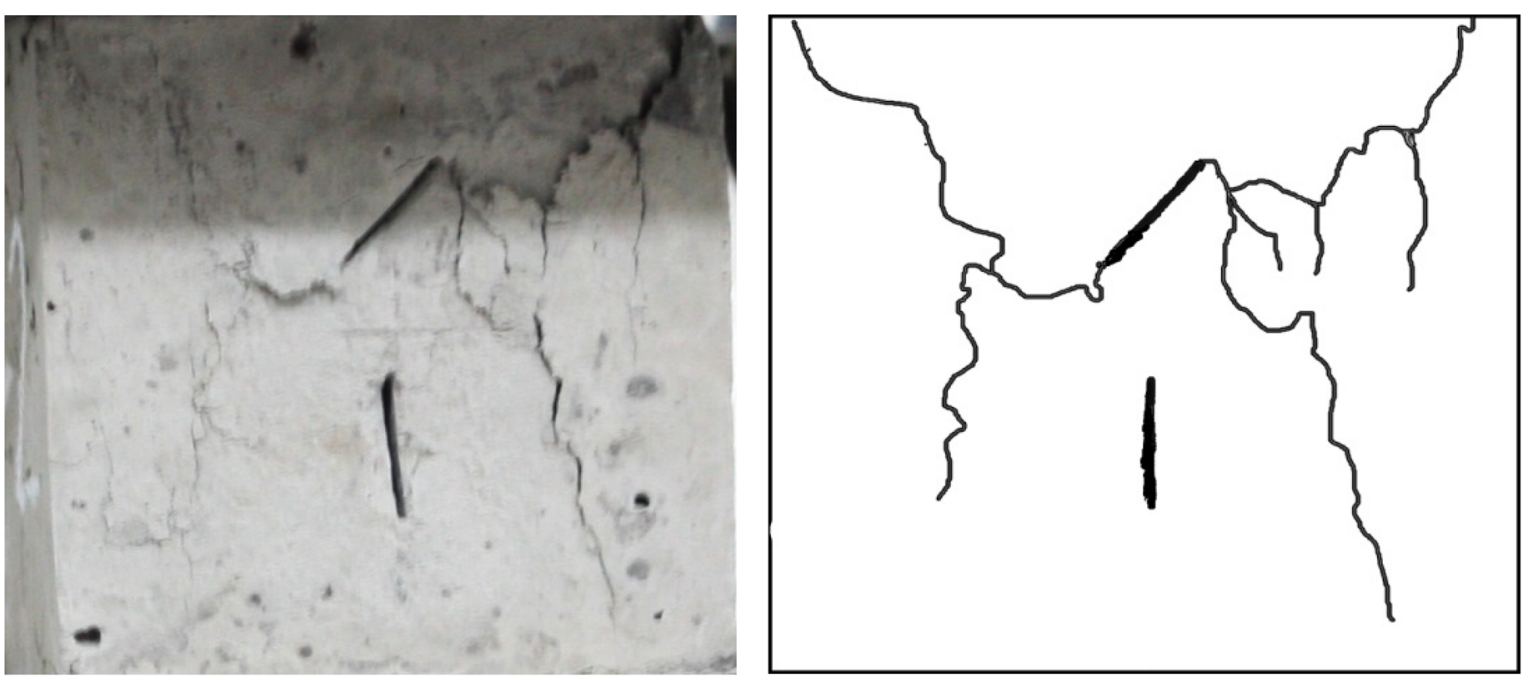

(b) $\mathrm{CQ} 45$
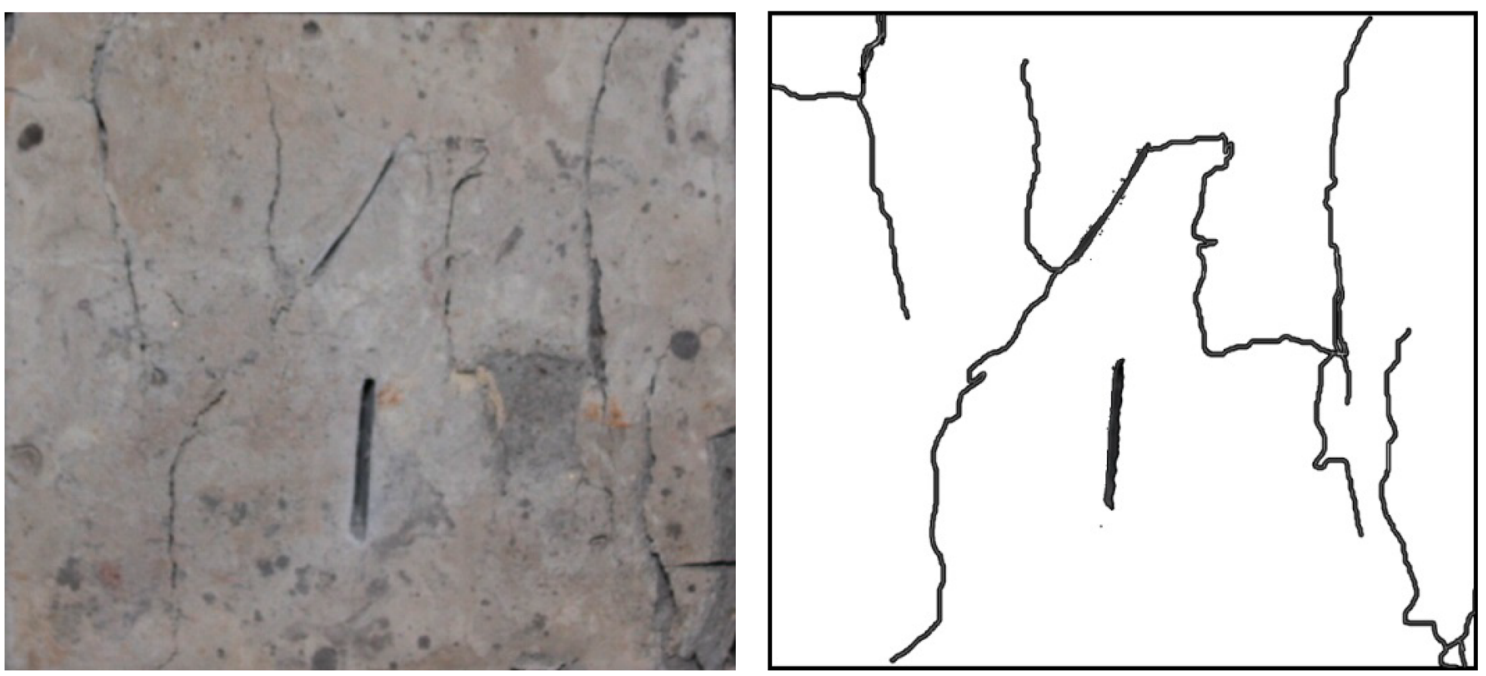

(c) CQ60

Fig. 6 Failure modes of rock-like specimens with non-parallel double cracks 

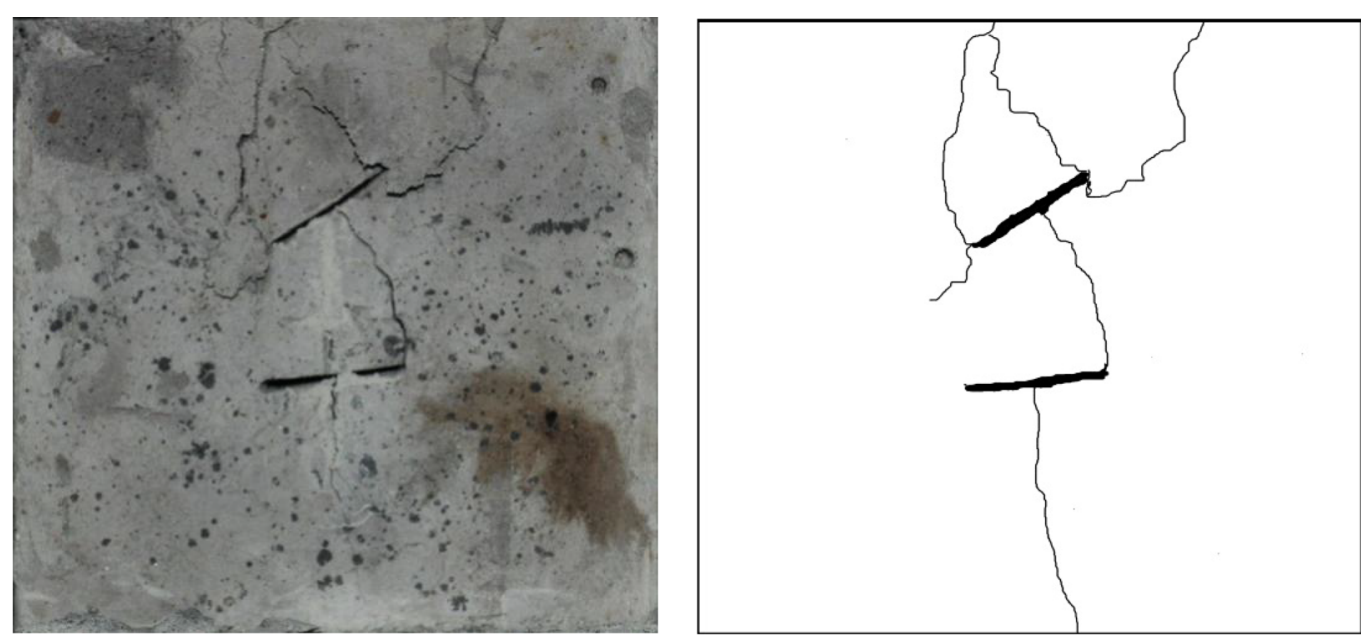

(d) $\mathrm{SQ} 30$
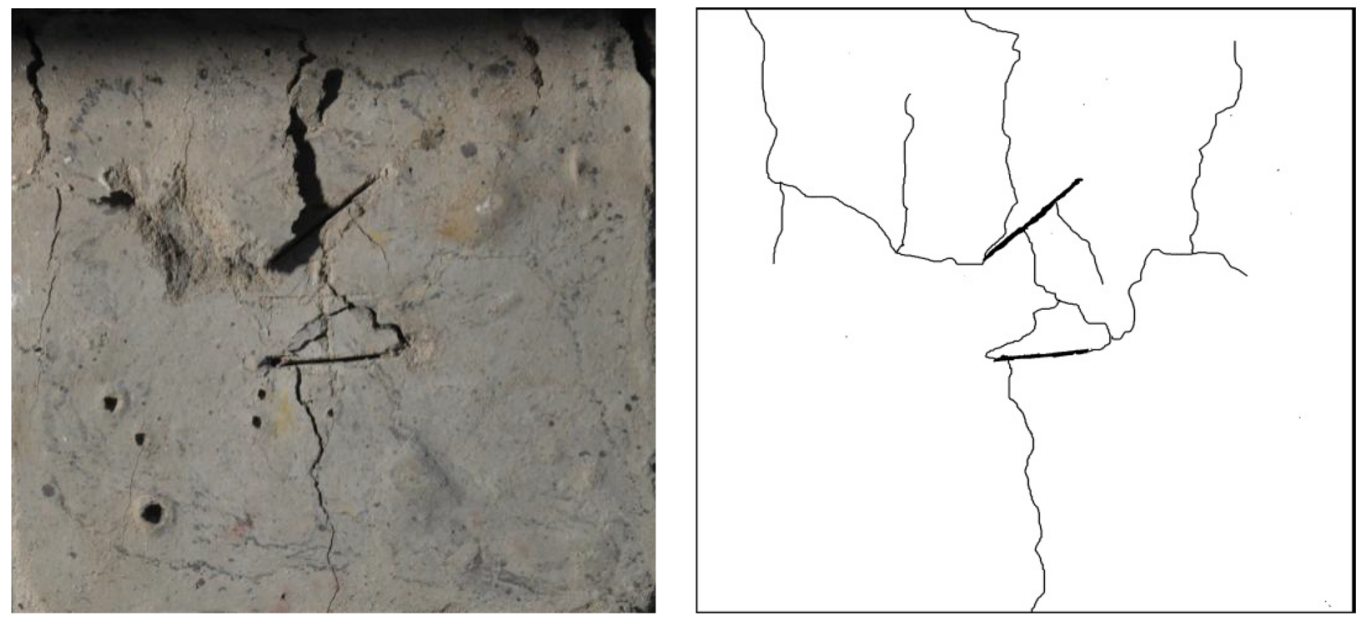

(e) $\mathrm{SQ45}$
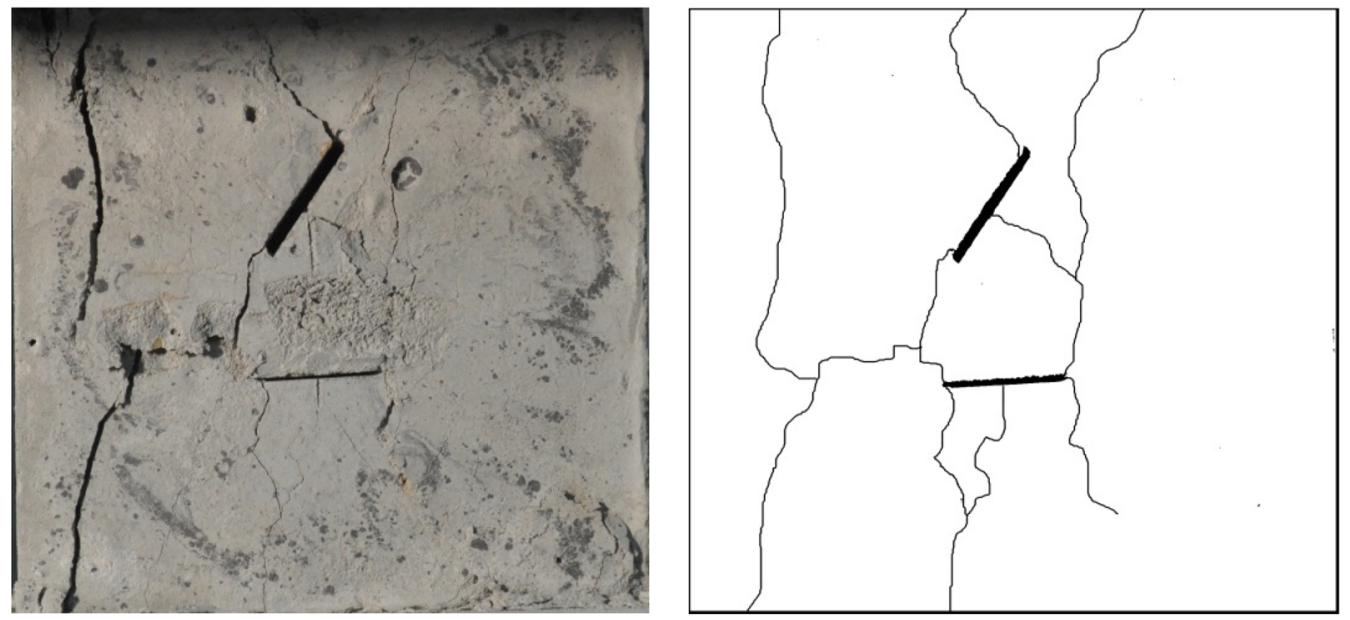

(f) SQ60

Fig. 6 continued 

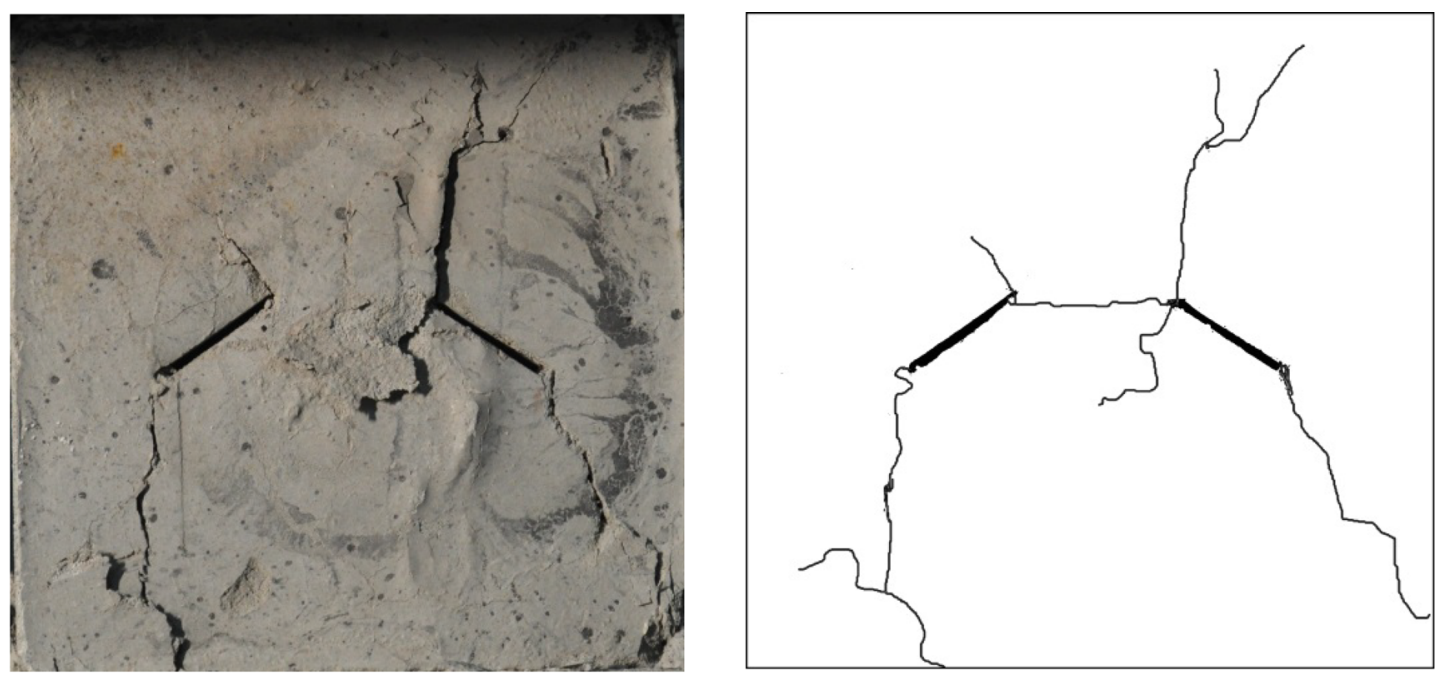

(g) DQ30
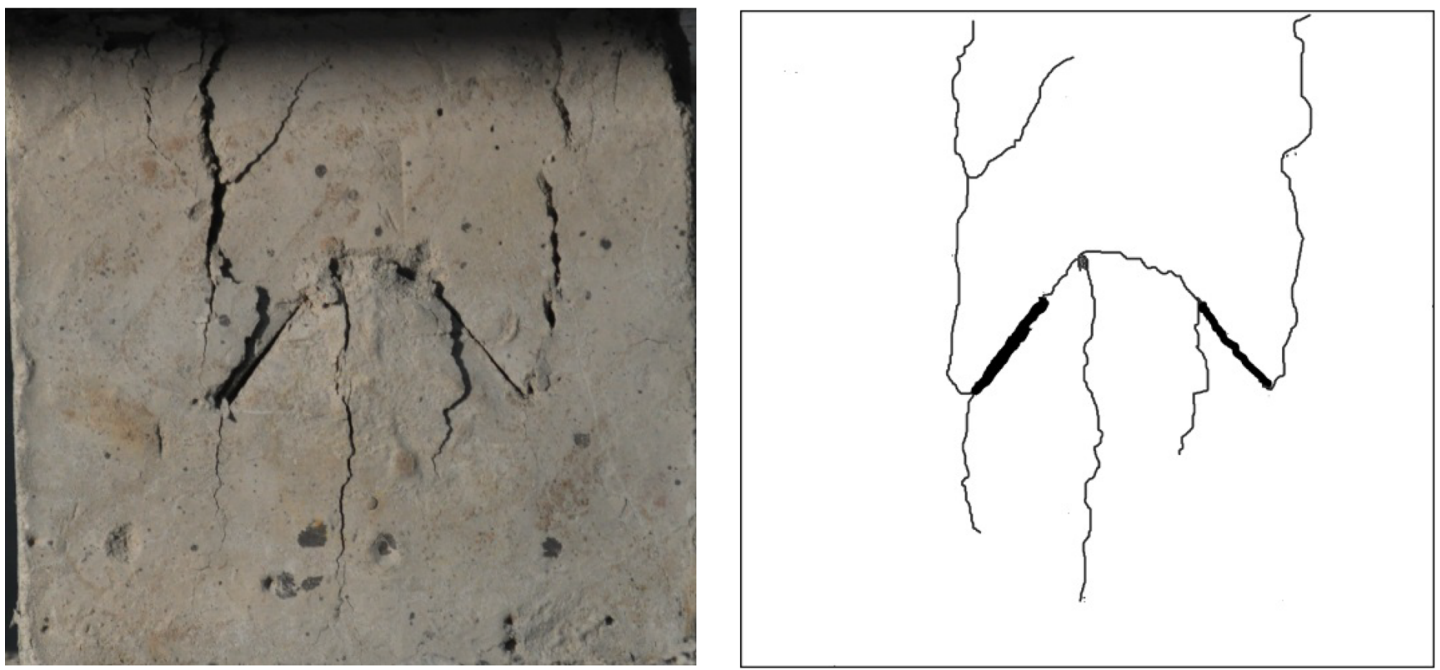

(h) DQ45
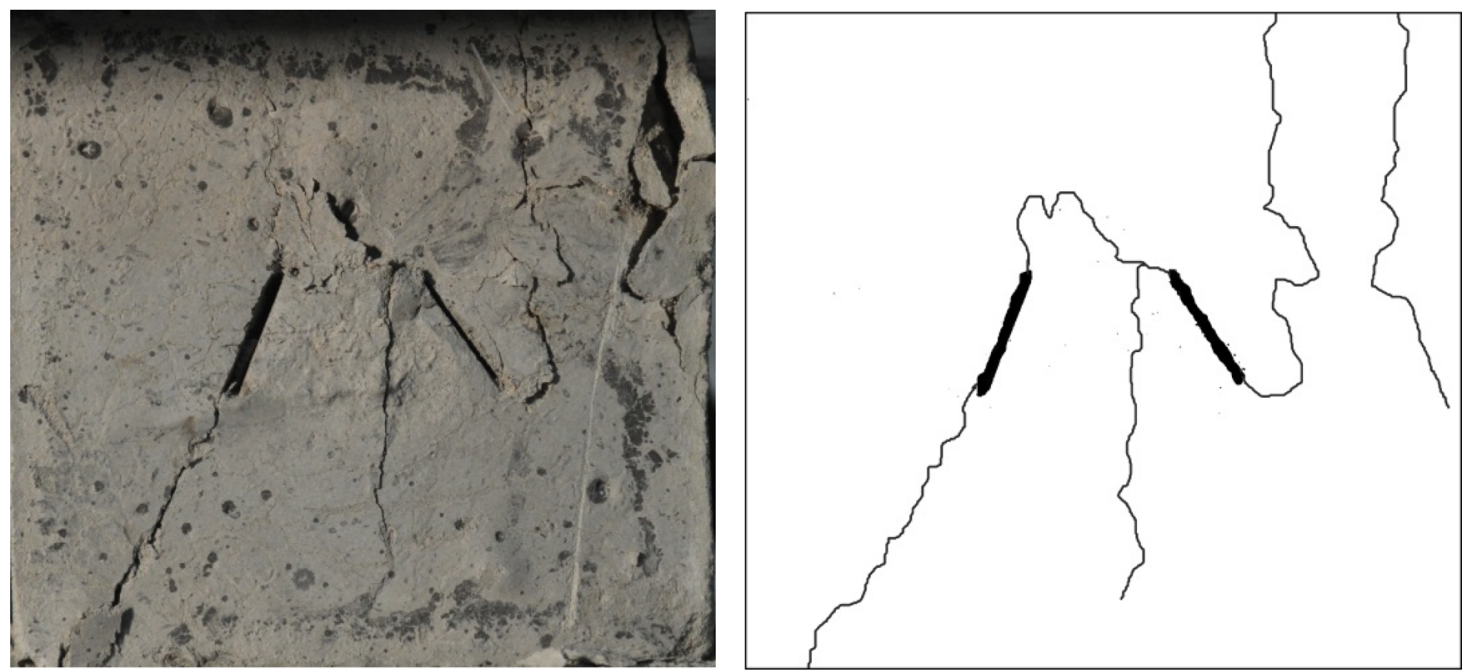

(i) DQ60

Fig. 6 continued 

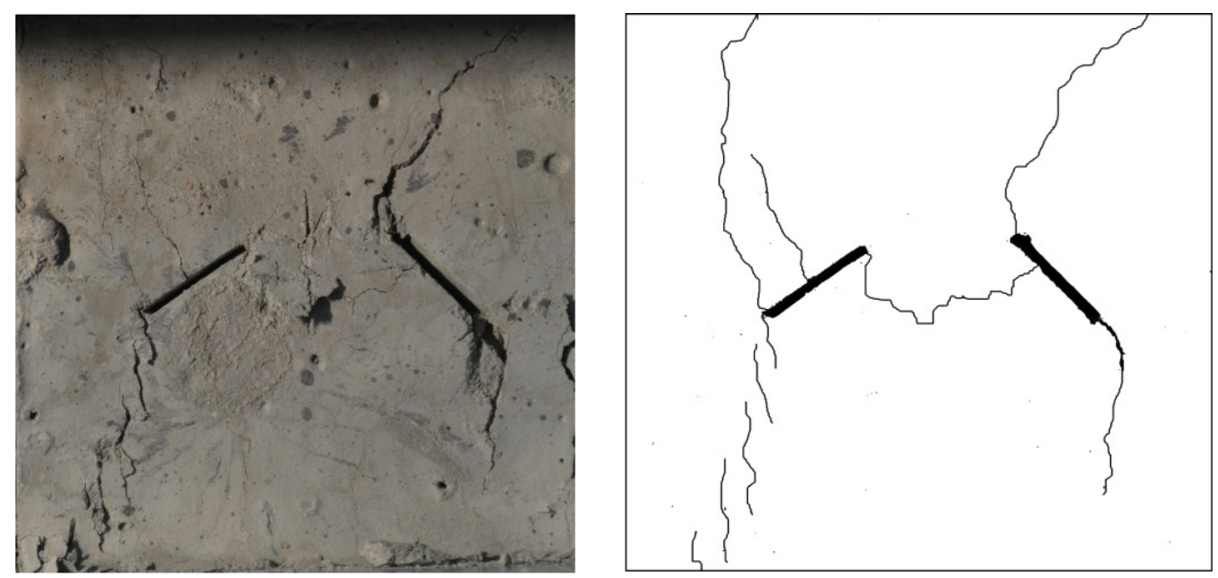

(j) SQ30-45
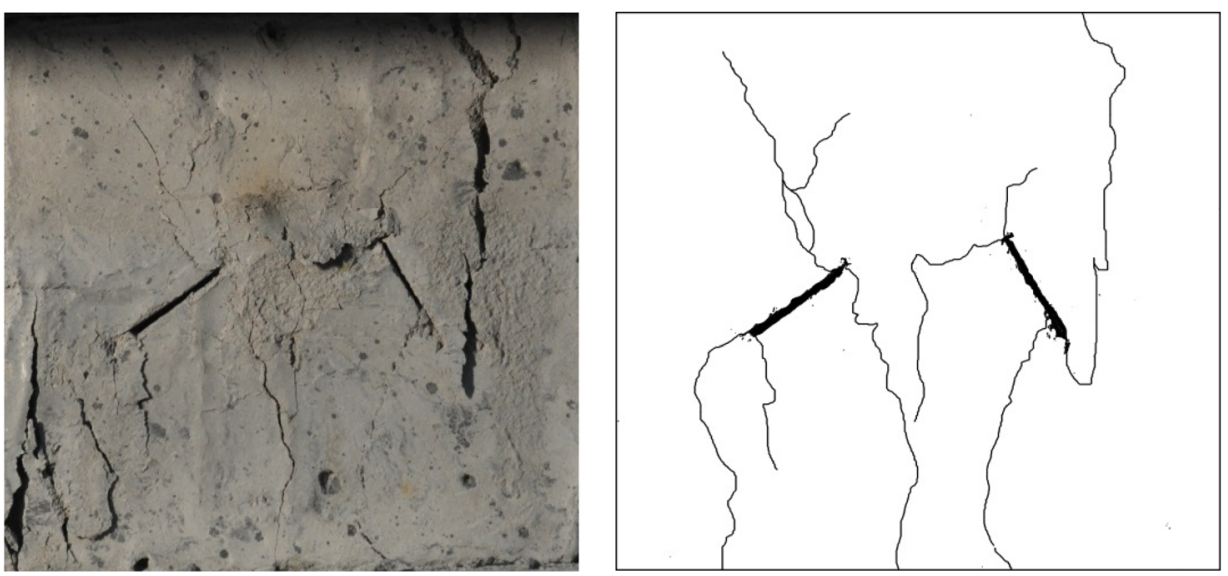

(k) $\mathrm{SQ} 30-60$
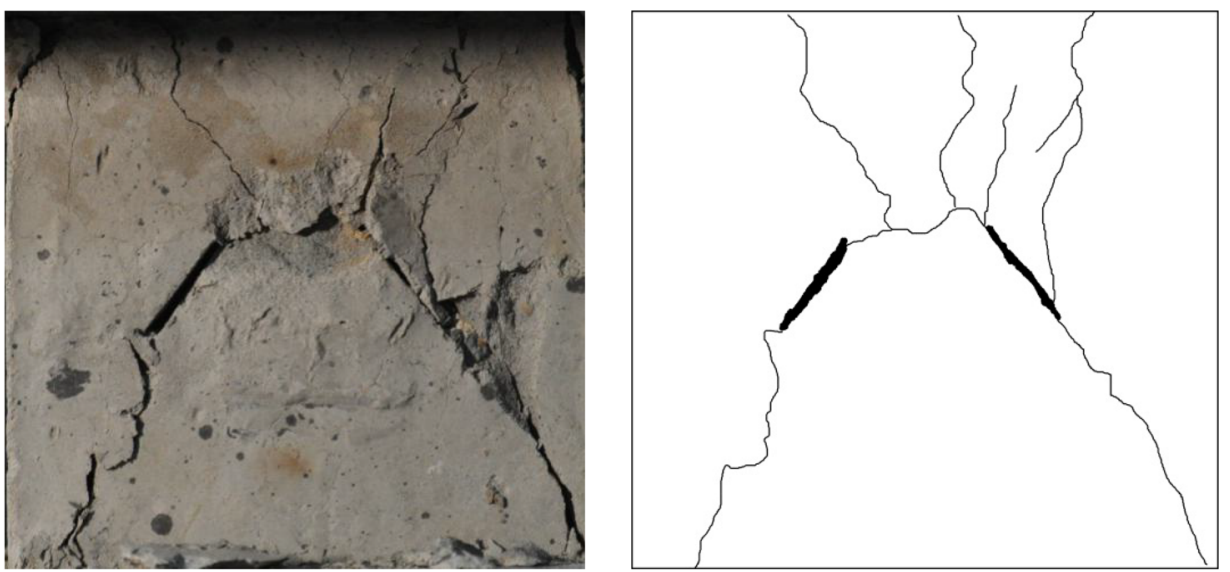

(l) $\mathrm{SQ} 45-60$

Fig. 6 continued

strength and degree of damage of the test block are determined. The experimental equipment is provided by the Top Coal Caving Center of the China University of Mining and Technology (Beijing). The ZBL-U5200 ultrasonic detector, as shown in Fig. 7, is used. The ultrasonic excitation impulse transmission voltage is selected to be $500 \mathrm{~V}$, the default setting for the transmitting pulse width is $0.04 \mu \mathrm{s}$, and the reading accuracy of the sound time measurement is $0.1 \mu \mathrm{s}$. Images of the experimental process are shown in Fig. 8. The ultrasonic-wave speed, and the 
Table 3 Coalescence failure types of the cracked test blocks

\begin{tabular}{|c|c|c|}
\hline $\begin{array}{l}\text { Coalescence } \\
\text { failure type }\end{array}$ & Description & Coalescence mode \\
\hline I & $\begin{array}{l}\text { Crack initiation position: end of the prefabricated crack } \\
\text { Wing cracks appeared at the end of the prefabricated cracks } \\
\text { The fracture surface is coarse and included crushed cuttings, which are peeling off in } \\
\text { some places }\end{array}$ & $\begin{array}{l}\text { Tension failure: wing crack and } \\
\text { tensile crack }\end{array}$ \\
\hline II-1 & $\begin{array}{l}\text { Crack initiation position: end of the prefabricated crack } \\
\text { Wing cracks appeared at the middle and end of the prefabricated cracks } \\
\text { The fracture surface is complete, and some parts are rough with mixed cuttings }\end{array}$ & $\begin{array}{l}\text { Tension and shear composite failure: } \\
\text { inclined secondary crack and wing } \\
\text { crack }\end{array}$ \\
\hline II-2 & $\begin{array}{l}\text { Crack initiation position: end of the prefabricated crack } \\
\text { Wing cracks appeared at the end of prefabricated cracks } \\
\text { Part of the fracture surface is coarse and includes crushed cuttings }\end{array}$ & $\begin{array}{l}\text { Tension and shear composite failure: } \\
\text { near the coplanar secondary crack } \\
\text { and tensile crack }\end{array}$ \\
\hline II-3 & $\begin{array}{l}\text { Crack initiation position: end of the prefabricated crack } \\
\text { Wing cracks appeared at the end of the prefabricated cracks } \\
\text { Most of the fracture surface is clean and smooth,while a part is coarse and included } \\
\text { crushed cuttings, which were peeling off }\end{array}$ & $\begin{array}{l}\text { Tension and shear composite failure: } \\
\text { near the coplanar secondary crack } \\
\text { and wing crack }\end{array}$ \\
\hline III-1 & $\begin{array}{l}\text { Crack initiation position: end of the prefabricated crack } \\
\text { Wing cracks appeared at the end of the prefabricated cracks } \\
\text { The fracture surface is very coarse and included crushed cuttings. Certain parts are } \\
\text { peeling off }\end{array}$ & $\begin{array}{l}\text { Shear failure: inclined secondary } \\
\text { crack and near the coplanar } \\
\text { secondary crack }\end{array}$ \\
\hline III-2 & $\begin{array}{l}\text { Crack initiation position: end of the prefabricated crack } \\
\text { Wing cracks appeared at the end of the prefabricated cracks } \\
\text { The fracture surface is very coarse and included with crushed cuttings; tensile cracks } \\
\text { appears on the fracture surface }\end{array}$ & $\begin{array}{l}\text { Shear failure: inclined secondary } \\
\text { crack and near the coplanar } \\
\text { secondary crack }\end{array}$ \\
\hline III-3 & $\begin{array}{l}\text { Crack initiation position: end of the prefabricated crack } \\
\text { Wing cracks appeared at the end of the prefabricated cracks; } \\
\text { external wing cracks do not appear } \\
\text { The fracture surface is very coarse and included crushed cuttings }\end{array}$ & $\begin{array}{l}\text { Shear failure:shear crack and near the } \\
\text { coplanar secondary crack }\end{array}$ \\
\hline III-4 & $\begin{array}{l}\text { Crack initiation position: end of the prefabricated crack } \\
\text { Wing cracks appeared at the end of the prefabricated cracks } \\
\text { The fracture surface is very coarse and included crushed cuttings; the local stress } \\
\text { concentration is significant. There are many microcracks and the cuttings are peeling } \\
\text { off }\end{array}$ & $\begin{array}{l}\text { Shear failure: secondary shear crack } \\
\text { and wing crack }\end{array}$ \\
\hline
\end{tabular}

amplitude and waveform of the first wave are recorded. The recorded acoustic parameters are presented in Tables 3 and 4 .

According to the acoustic parameters listed in Tables 4 and 5 , the wave velocity variation diagram is drawn, as shown in Fig. 9. In Tables 4, 5 and Fig. 9, it is observed that the variation trend of the wave velocity is approximately the same, before and after uniaxial compression; the wave velocity decreases within a certain extent, after uniaxial compression test. This is because the propagation and coalescence of the internal cracks within the specimen, and the increases in the internal flaws during uniaxial compression. When ultrasonic waves passes through these flaws, they are reflected and refracted, causing the additional attenuation of sound energy. The variation of the wave velocity of specimen SQ45 is the maximum, indicates that the specimen has a high extent of failure and internal microcrack development. The variation of the wave velocity of specimen DQ45 shows small changing. The failure mode of the test block is examined visually, and shear failure along the crack direction is found. The block broke along the main crack, and the degree of secondary crack development is low; therefore, the wave velocity do not decrease significantly. The wave velocity at which an ultrasonic wave passes through the test block reflected the residual strength of the test block to a 
Table 4 Acoustic parameters of the test block before uniaxial compression

\begin{tabular}{lllll}
\hline Number & Acoustic time $(\mu \mathrm{s})$ & Wave velocity $(\mathrm{km} / \mathrm{s})$ & Wave amplitude $(\mathrm{dB})$ & Ranging $(\mathrm{mm})$ \\
\hline CQ30 & 36.0 & 2.61 & 153.54 & 100 \\
CQ45 & 40.0 & 2.25 & 149.25 & 100 \\
CQ60 & 38.8 & 2.58 & 144.36 & 100 \\
SQ30 & 36.8 & 2.73 & 143.69 & 100 \\
SQ45 & 38.4 & 2.62 & 146.02 & 100 \\
SQ60 & 36.4 & 2.76 & 148.56 & 100 \\
DQ30 & 38.0 & 2.65 & 150.79 & 100 \\
DQ45 & 37.6 & 2.66 & 155.08 & 100 \\
DQ60 & 37.2 & 2.70 & 154.58 & 100 \\
SQ30-45 & 38.8 & 2.58 & 154.94 & 100 \\
SQ30-60 & 37.6 & 2.66 & 153.02 & 100 \\
SQ45-60 & 36.4 & 2.76 & 155.12 & 100 \\
\hline
\end{tabular}

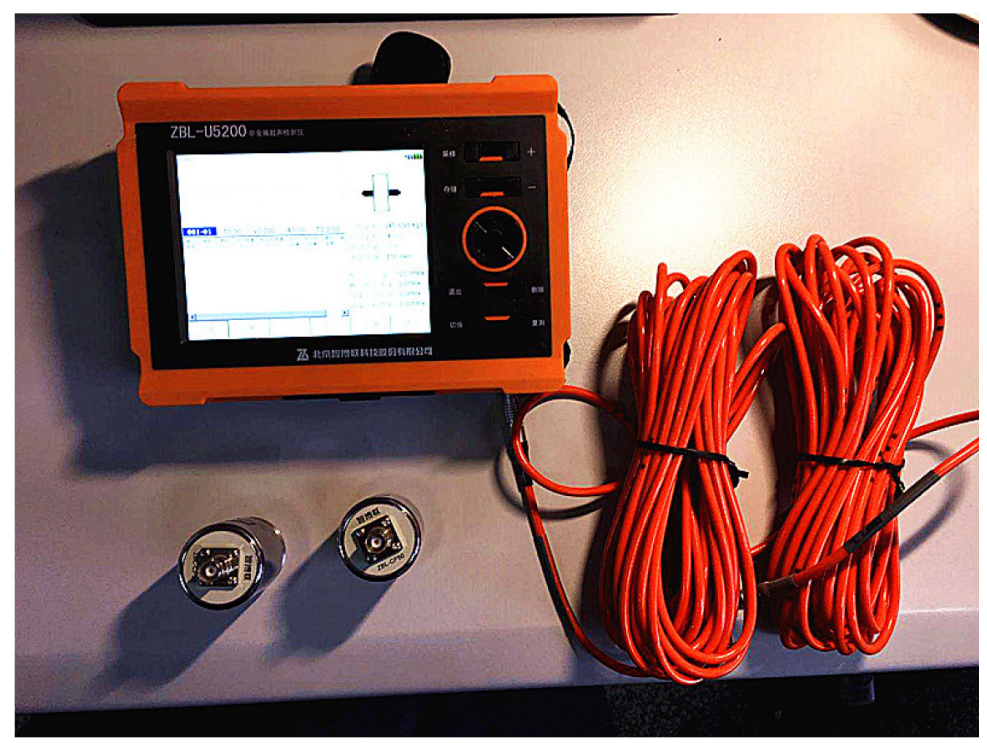

Fig. 7 Ultrasonic detector

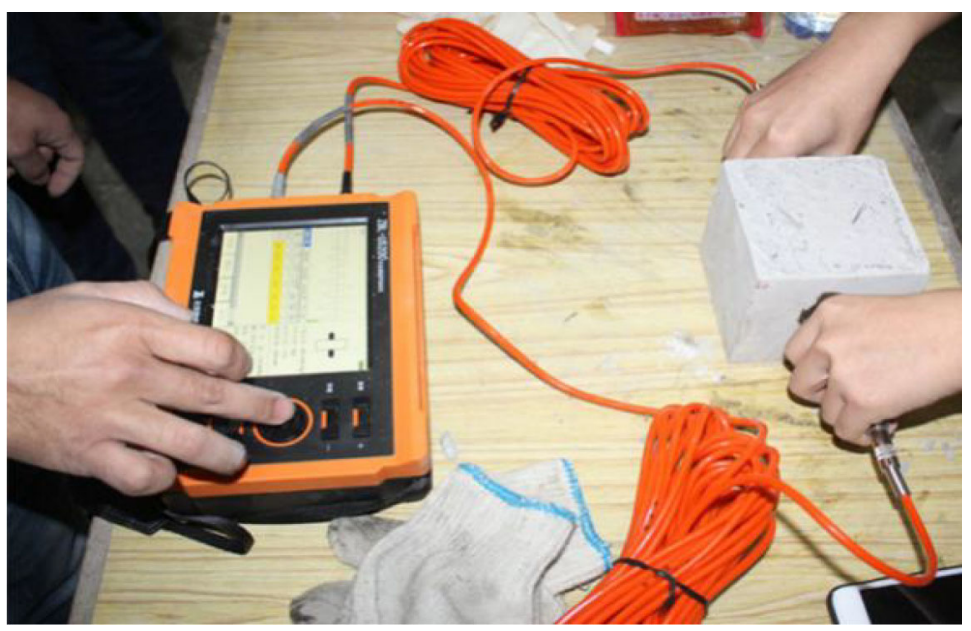

Fig. 8 Ultrasonic testing 
Table 5 Acoustic parameters of the test block after uniaxial compression

\begin{tabular}{lllll}
\hline Number & Acoustic time $(\mu \mathrm{s})$ & Wave velocity $(\mathrm{km} / \mathrm{s})$ & Wave amplitude $(\mathrm{dB})$ & Ranging $(\mathrm{mm})$ \\
\hline CQ30 & 46.4 & 2.17 & 143.51 & 100 \\
CQ45 & 47.2 & 1.81 & 144.26 & 100 \\
CQ60 & 45.6 & 2.19 & 140.66 & 100 \\
SQ30 & 42.3 & 2.13 & 136.49 & 100 \\
SQ45 & 44.8 & 1.91 & 143.2 & 100 \\
SQ60 & 46.4 & 2.16 & 132.99 & 100 \\
DQ30 & 43.2 & 2.11 & 138.4 & 100 \\
DQ45 & 43.6 & 2.29 & 153.6 & 100 \\
DQ60 & 45.6 & 2.18 & 132.31 & 135.36 \\
SQ30-45 & 45.6 & 2.20 & 152.28 & 100 \\
SQ30-60 & 46.0 & 2.19 & 130.82 & 100 \\
SQ45-60 & 44.8 & 2.23 & 100 \\
\hline
\end{tabular}

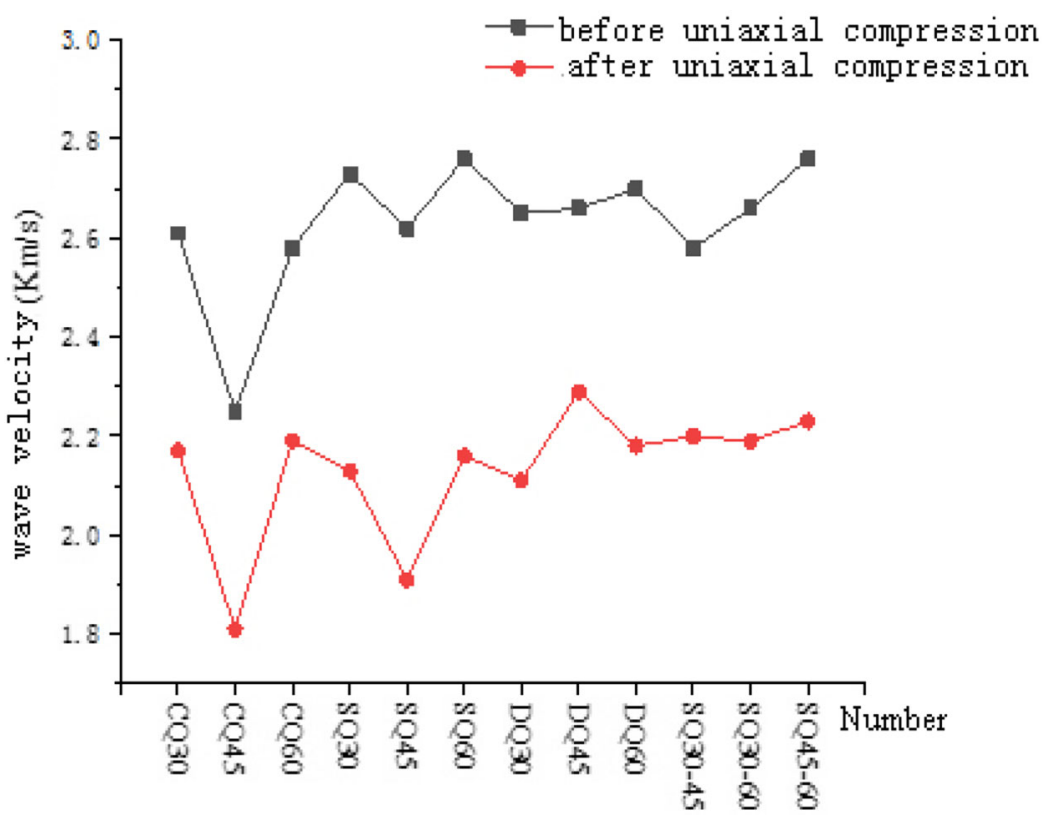

Fig. 9 Wave-velocity curves, before (black square) and after (red circle) the uniaxial compression test

certain extent. In this manner, the degree of damage to the specimen can be estimated by the magnitude of the wave velocity (Fig. 10).

The recorded acoustic time in the experiment reflectes the pick-up time when the first wave reaches the receiving pole; the variation trend of the acoustic time is approximately the same, before and after uniaxial compression. Before uniaxial compression, the acoustic time of specimens CQ30, SQ45, SQ45-60 are slower than those of the other combinations, and the acoustic time of specimen CQ45 is the fastest. After uniaxial compression, the acoustic time increases in different degrees.
For the horizontal and inclined crack combination, the change in the acoustic time is different before and after uniaxial compression. The acoustic time of specimen SQ45 is longest, before uniaxial compression. The relationship of the acoustic time shows that the trend of SQ30 < SQ45 < SQ60 after uniaxial compression, which indicates that the test block is more prone to damage with the increases in the crack inclination angle. This is the same as the change rule, when the peak stress is compared, further proved the influence of the crack inclination on the strength of the specimen. In the vertical and inclined crack combination after uniaxial compression, the variation trend of the acoustic time is the same. The acoustic time increases considerably and the overall gap 


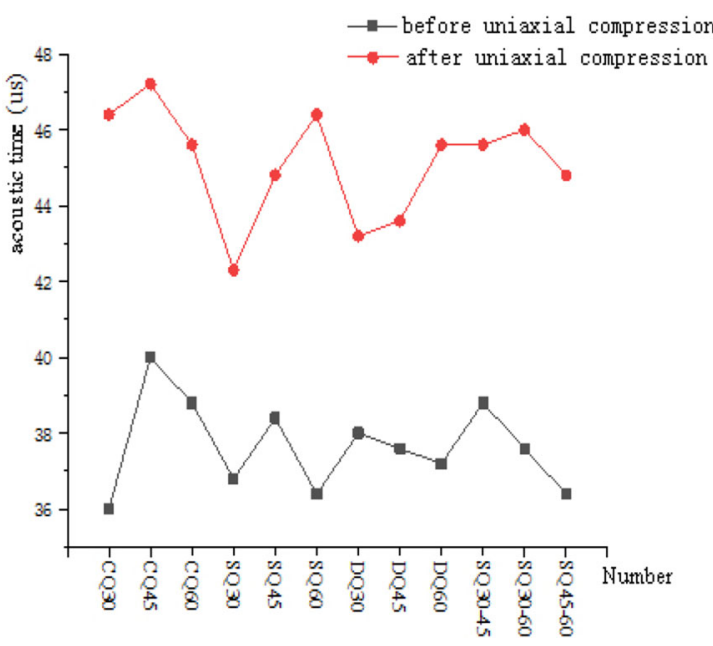

Fig. 10 Sound variation, before (black square) and after (red circle) the uniaxial compression test

decreases; the acoustic-time difference between the blocks decreases, and the acoustic time do not increase with the increasing of the crack angle inclination. The results demonstrate that the degree of damage to the test blocks is similar after uniaxial compression, and it is mainly affected by vertical cracks. In addition, for the combination of inclined cracks at the same dip angle, the variation trend of the acoustic time is different; the acoustic time increased with the increase in the crack angle inclination, i.e., with the increase in the crack inclination angle, the failure degree of the test block increases. For the combination of inclined cracks at different inclination angles, the variation trend of the acoustic time shows different. The acoustic time of test block SQ45-60 is the minimum before and after the uniaxial compression test.

\section{Conclusions}

In this study, non-parallel double-crack specimens were fabricated with various crack inclinations. Fracture experiments were conducted on these rock-like specimens thorough which the laws of initiation, propagation, and penetration of non-parallel double cracks were studied. The findings can be summarized:

(1) The crack angle has large influence on the strength of the specimen, which decreases with the increasing of the crack inclination angle for a combination of two different inclinations. For a combination of inclined cracks at the same dip angle in different directions, the specimen strength is the maximum.

(2) Based on the analyzing of the final failure patterns, it is determined that with the increases in the crack inclination angle, the main failure form of the test block changes gradually from tensile failure to shear failure. In particular, for a crack angle $45^{\circ}$, shear failure is the dominant failure mode. The failure modes of the specimens are divided into three categories: tension coalescence failure, tension and shear composite coalescence failure, and shear coalescence failure.

After the uniaxial compression test, the ultrasonic wave velocity generally shows a decreasing trend and the acoustic time shows an increasing trend, and the wave amplitude shows a decreasing tendency. The variation trends of the wave velocity and acoustic time are almost the same as those before the experiment.

Acknowledgements The authors gratefully acknowledge the financial support from the National Key Research and Development Plan (No. 2018YFC0604501) and the Yue Qi Distinguished Scholar Project, China University of Mining \& Technology, Beijing (No. 800015Z1138).

Open Access This article is distributed under the terms of the Creative Commons Attribution 4.0 International License (http://crea tivecommons.org/licenses/by/4.0/), which permits unrestricted use, distribution, and reproduction in any medium, provided you give appropriate credit to the original author(s) and the source, provide a link to the Creative Commons license, and indicate if changes were made.

\section{References}

Afolagboye LO, He JM, Wang SJ (2017) Crack initiation and coalescence behavior of two non-parallel flaws. Geotech Geol Eng 36:105-133. https://doi.org/10.1007/s10706-017-0310-0

Bobet A, Einstein HH (1998) Fracture coalescence in rock-type materials under uniaxial and biaxial compression. Int $\mathrm{J}$ Rock Mech Min 35:863-888. https://doi.org/10.1016/s01489062(98)00005-9

Brooks Z, Ulm FJ, Einstein HH (2013) Environmental scanning electron microscopy (ESEM) and nanoindentation investigation of the crack tip process zone in marble. Acta Geotech 8:223-245. https://doi.org/10.1007/s11440-013-0213-Z

Chen YS, Li N, Han X, Pu YB, Liao QR (2005) Research on crack developing process in non-interpenetrated crack media by using CT. CJRME 15:2665-2670

Huang YH, Yang SQ, Zhao J (2016) Three-dimensional numerical simulation on triaxial failure mechanical behavior of rock-like specimen containing two unparallel fissures. Rock Mech Rock Eng 49:1-19. https://doi.org/10.1017/s00603-016-1081-2

Lee H, Jeon S (2011) An experimental and numerical study of fracture coalescence in pre-cracked specimens under uniaxial compression. Int J Solids Struct 48:979-999. https://doi.org/10. 1016/j.ijsolstr.2010.12.001

Li TC, Lv HB, Wang H (2010) CT real-time scanning tests on double cracks propagation under uniaxial compression. Rock Soil Mech 31:9-14

Pu CZ, Cao P, Zhao YL, Zhang XY, Yi YL, Liu YK (2010) Numerical analysis and strength experiment of rock-like materials with multi-fissures under uniaxial compression. Rock Soil Mech 31:3661-3666 
Ren ZY, Pan WD, Liu SM, Zhou S (2017) Numerical simulation of non-parallel double crack propagation and coalescence in rock specimen. J Min Sci Technol 2:33-41

Shao DL, Li SC, Li MT, Zhang B, Zhang GS (2011) Study of failure analysis and the acoustic emission signature of 3-D crack from different origins under uniaxial compression. J Shandong Univ Eng Sci 41:131-136

Shen JJ, Liu WT, Zhang Q, Xu K (2016) Numerical simulation and mechanical experiment on failure behaviour of specimens containing pre-existing two flaws. J Liaoning Tech Univ Nat Sci 35:1397-1401

Wong RHC, Chau KT (1998) Crack coalescence in a rock-like material containing tow cracks. Int $J$ Rock Mech Min 35:147-164. https://doi.org/10.1016/s0148-9062(97)00303-3

Wong LNY, Einstein HH (2009a) Crack coalescence in molded gypsum and Carrara marble: part 1-macroscopic observations and interpretation. Rock Mech Rock Eng 42:475-511. https:// doi.org/10.1007/s00603-008-0002-4

Wong LNY, Einstein HH (2009b) Crack coalescence in molded gypsum and Carrara marble: part 2-macroscopic observations and interpretation. Rock Mech Rock Eng 42:513-545. https:// doi.org/10.1007/s00603-008-0003-3
Yang SQ (2013) Study of strength failure and crack coalescence behavior of sandstone containing three pre-existing fissures. Rock Soil Mech 34:31-39

Yang SQ, Dai YH, Han LJ, He YN, Li YS (2009) Uniaxial compression experimental research on deformation and failure properties of brittle marble specimen with pre-existing fissures. CJRME 28:2391-2404

Yang SQ, Liu XR, Jing HW (2013) Experimental investigation on fracture coalescence behavior of red sandstone containing two unparallel fissures under uniaxial compression. Int J Rock Mech MIN 63:82-92. https://doi.org/10.1016/j.ijrmms.2013.06.008

Zhang XP, Liu Q, Wu S, Tang X (2015a) Crack coalescence between two non-parallel flaws in rock-like material under uniaxial compression. Eng Geol 199:74-90. https://doi.org/10.1016/j. enggeo.2015.10.007

Zhang B, Li SC, Yang XY, Zhang DF, Wang Q, Cai W, Deng ZQ (2015b) Mechanical property of rock-like material with intersecting multiflaws under uniaxial compression. CJRME 34:1777-1785

Zhu ZD, Lin HX, Sun YL (2016) An experimental study of internal $3 \mathrm{D}$ crack propagation and coalescence in transparent rock. Rock Soil Mech 37:913-921+928 